\title{
Noninvasive Ventilation Influenced the Survival of Extreme Super-Super Obese with Obesity Hypoventilation Syndrome
}

\author{
Mohammed Nasser Alwadai, Awad Alqahtani, Omprakash Palanivel \\ Intensive Care Unit, Aseer Central Hospital, Abha, Aseer Region, Kingdom of Saudi Arabia
}

\section{Abstract}

Recent studies conclude noninvasive ventilation (NIV) as a standard first-line therapy for any respiratory failure. The efficacy of NIV in obesity is well defined. In this context, the effectiveness of NIV in extreme super-super obese patients with obesity hypoventilation syndrome is not well studied, and the usage of NIV is controversial because of rare incidence. However, identifying the right patient, right timing, right clinical expertise, correct positions, and right appropriate NIV settings can produce positive results. Therefore, we present a unique case of a 32-year-old male weighing $283 \mathrm{~kg}$, with body mass index $>92 \mathrm{~kg} / \mathrm{m}^{2}$ and carbon dioxide retention, whose symptoms were worsening despite adequate conventional treatment. He received continuous NIV for $70 \mathrm{~h}$ using a standard protocol with close monitoring. There was improvement in the patient vitals and medical condition with significant reduction in arterial carbon dioxide tension, leading to reduction in the length of intensive care unit stay and prevention of further complications. Long-term research is encouraged to validate NIV effectiveness in this group of patients.

Keywords: Expiratory positive airway pressure, inspiratory positive airway pressure, noninvasive ventilation, obesity hypoventilation syndrome, obstructive sleep apnea

\section{INTRODUCTION}

Obesity is a universal health concern in recent years, and it is one of the leading causes of preventable deaths in Saudi Arabia, with an obesity prevalence of $33.7 \%{ }^{[1]}$ According to the Obesity Medicine Association, obesity is "a chronic, relapsing, multifactorial, neurobehavioral disease, wherein an increase in body fat promotes adipose tissue dysfunction and abnormal fat mass physical forces, resulting in adverse metabolic, biomechanical, and psychosocial health consequences."[2] The body mass index (BMI) is a crude and easy tool that is commonly used to measure obesity, and it is the value derived from a person's weight in kilograms $(\mathrm{kg})$ divided by the square of his/her height in meters $\left(\mathrm{m}^{2}\right)$. In general, the World Health Organization quotes that a BMI $\geq 30 \mathrm{~kg} / \mathrm{m}^{2}$ as obese. Obesity is subcategorized into the following grades: Grade 1 (BMI 30 to $<35 \mathrm{~kg} / \mathrm{m}^{2}$ ), Grade 2 (BMI 35 to $<40 \mathrm{~kg} / \mathrm{m}^{2}$ ), and Grade $3\left(\mathrm{BMI}>40 \mathrm{~kg} / \mathrm{m}^{2}\right) .{ }^{[3]}$ Table 1 summarizes the Spanish Society for the study of Obesity (SEEDO) classification. ${ }^{[4]}$ Despite increased awareness over the past decades, obesity, particularly Class III, is continuing to rise. ${ }^{[5-7]}$ With a rise in obesity, the incidence of obesity hypoventilation

\begin{tabular}{|l|l|}
\hline \multicolumn{2}{|c|}{ Access this article online } \\
\hline Quick Response Code: & Website: \\
& www.ijrconline.org \\
\cline { 2 - 2 } & \\
\hline
\end{tabular}

syndrome (OHS) has increased significantly, with almost 50\% of people with BMI $>50 \mathrm{~kg} / \mathrm{m}^{2}$ being hospitalized globally. ${ }^{[7]}$ OHS is a combination of obesity (BMI $>30 \mathrm{~kg} / \mathrm{m}^{2}$ ), daytime hypercapnia (arterial carbon dioxide tension $>45 \mathrm{mmHg}$ ), and sleep-disordered breathing, after exclusion of other disorders that may cause alveolar hypoventilation. Besides, obstructive sleep apnea (OSA) is also associated with hypoventilation in $90 \%$ of OHS patients. ${ }^{[5,6]}$ Currently, OHS has become a significant indication for noninvasive ventilation (NIV). ${ }^{[7-9]}$ However, there is no report from Saudi Arabia on the use of NIV in extreme super-super obese-associated OHS. Choosing to administer NIV in such patients is unique and challenging. In this case report, we describe the first-ever successful application of NIV in an extreme super-super obese individual and the possibility of its use effectively in the intensive care unit (ICU) in future.

Address for correspondence: Mr. Omprakash Palanivel, Cardiorespiratory Therapist, Aseer Central Hospital, Abha, Aseer Region, Kingdom of Saudi Arabia. E-mail: omarprakash77@gmail.com

This is an open access journal, and articles are distributed under the terms of the Creative Commons Attribution-NonCommercial-ShareAlike 4.0 License, which allows others to remix, tweak, and build upon the work non-commercially, as long as appropriate credit is given and the new creations are licensed under the identical terms. For reprints contact: reprints@medknow.com

How to cite this article: Alwadai $\mathrm{MN}$, Alqahtani $\mathrm{A}$, Palanivel $\mathrm{O}$. Noninvasive ventilation influenced the survival of extreme super-super obese with obesity hypoventilation syndrome. Indian J Respir Care 2020;9:116-9.

Received: $18-07-2019$ Accepted: $12-12-2019$

Revised: 20-10-2019 Published: 08-01-2020 


\begin{tabular}{ll}
\hline $\begin{array}{l}\text { Table 1: Obesity classification } \\
\text { Study of } \text { Obesity) }\end{array}$ \\
\hline BMI $\left(\mathbf{k g} / \mathbf{m}^{2}\right)$ & Classification \\
\hline$<18.5$ & Underweight \\
$18.5-24.9$ & Normal weight \\
$25.0-26.9$ & Overweight \\
$27.0-34.9$ & Class I obese \\
$35.0-39.9$ & Class II obese \\
$40.0-49.9$ & Class III obese \\
$50-59.9$ & Class IV super obese \\
$>60$ & Class V extreme super-super obese \\
\hline
\end{tabular}
BMI: Body mass index

\section{Case Report}

A 32-year-old Saudi male with no comorbidities and independent in his activities of daily living presented with a history of breathlessness on and off for the past 3 months. It worsened with travel to $2200-\mathrm{m}$ high altitude. In the emergency room, the patient was drowsy with the chief complaints of severe dyspnea, headache, myalgia, and swelling and pain in the lower limb. There was no history of any chronic respiratory diseases. He was afebrile. His heart rate was $115-120$ beats/min and regular, respiratory rate was $35-40$ breaths/min, blood pressure was $150 / 90 \mathrm{mmHg}$, and oxygen saturation was $74 \%$ on room air. Physical examination revealed a weight of $283 \mathrm{~kg}$, BMI $>92 \mathrm{~m}^{2}$, height of $175 \mathrm{~cm}$ with a neck circumference of $55 \mathrm{~cm}$, cyanotic nail beds, mild jugular distension, and higher central fat distribution. He was drowsy but easily arousable. Glasgow Coma Scale (GCS) score was 11. In the emergency room, he was treated with $\mathrm{O}_{2} 15 \mathrm{~L} / \mathrm{min}$, and the oxygen saturation rose to $90 \%-91 \%$. His blood biochemistry was within normal limits. His treatment included intravenous fluids $(5 \%$ dextrose normal saline with $20 \mathrm{mEq}$ potassium chloride added, hydrocortisone $100 \mathrm{mg}$ TID, amoxicillin $1 \mathrm{~g}$ TID, inhaled ipratropium bromide $6^{\text {th }}$ hourly, inhaled salbutamol $6^{\text {th }}$ hourly, furosemide $20 \mathrm{mg}$ BID, and unfractionated heparin 7500 SC TID). Arterial blood gas analysis (ABG) was obtained, and sputum for cultures was collected. Anteroposterior chest X-ray revealed bilateral increased bronchovascular markings and cardiomegaly [Figure 1]. Electrocardiogram showed sinus tachycardia. Echocardiography showed dilated right ventricle and mild tricuspid regurgitation. A computed tomography (CT) scan could not be performed to detect pulmonary embolism because the CT table could not accommodate his weight. His initial ABG in the emergency room showed hypoxia and respiratory acidosis $(\mathrm{pH} 7.26$, $\mathrm{PCO}_{2} 86 \mathrm{mmHg}, \mathrm{PO}_{2} 27.9 \mathrm{mmHg}$, and $\mathrm{HCO}_{3} 29.6 \mathrm{mmol} / \mathrm{L}$ ).

The diagnosis at admission was OHS with OSA, cor pulmonale, and cellulitis. His condition deteriorated subsequently with desaturation to $76 \%$ even with $15 \mathrm{~L} / \mathrm{min}$ of oxygen. Therefore, the patient was transferred to the ICU for further management. A trial of NIV was given along with other conventional treatment. $\mathrm{ABG}$ repeated before NIV showed severe respiratory

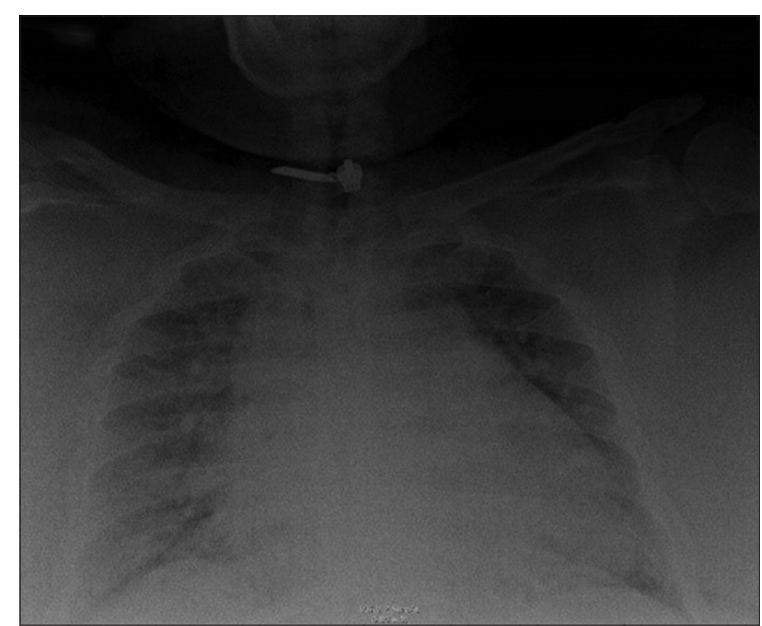

Figure 1: X-ray admission

acidosis $\left(\mathrm{pH} 7.15, \mathrm{PO}_{2} 65 \mathrm{mmHg}, \mathrm{PCO}_{2} 113 \mathrm{mmHg}\right.$, and $\mathrm{HCO}_{3} 27.6 \mathrm{mmol} / \mathrm{L}$ ) [Table 2]. Intubation and invasive ventilation was planned if the respiratory rate increased to $>40$ breaths/min or if there was any drop in GCS level. To avoid aspiration and to deliver adequate ventilation, high Fowler's position was adopted. The NIV-Bi-level ST Philips Respironics V 60, California, USA) is a single-circuit, pressure-targeted, nonvent mask provided with a calibrated leak. The following settings were used: respiratory rate was set at $25 \mathrm{~b} / \mathrm{min}$ as backup, inspiratory positive airway pressure (IPAP) of 10 $\mathrm{cmH}_{2} \mathrm{O}$ was initiated to overcome upper airway resistance and to reduce the work of breathing (WOB), and expiratory positive airway pressure (EPAP) of $5 \mathrm{cmH}_{2} \mathrm{O}$ was initiated to prevent alveoli collapse at the end of each respiratory cycle. To provide more time for expiration and to reduce WOB, an inspiration and expiration time ratio was set at 1:4. After $2 \mathrm{~h}$ of NIV, ABG showed $\mathrm{pH} 7.12, \mathrm{PCO}_{2} 136 \mathrm{mmHg}$, and $\mathrm{PO}_{2} 77.3 \mathrm{mmHg}$. IPAP was increased in steps of $3 \mathrm{cmH}_{2} \mathrm{O}$ and EPAP in steps of $1 \mathrm{cmH}_{2} \mathrm{O}$, every $15 \mathrm{~min}$ based on the WOB, minute ventilation, respiratory rate, and $\mathrm{ABG}$ results. Adequate tidal volume was reached with IPAP $22 \mathrm{cmH}_{2} \mathrm{O}$ and EPAP $10 \mathrm{cmH}_{2} \mathrm{O}$ (as tolerated by the patient). Subsequently, as the patient improved, NIV could be gradually reduced to IPAP of $12 \mathrm{cmH}_{2} \mathrm{O}$ and EPAP of $5 \mathrm{cmH}_{2} \mathrm{O}$ based on $\mathrm{ABG}$ and respiratory mechanics. $\mathrm{FiO}_{2}$ was adjusted between $45 \%$ and $80 \%$ to keep the $\mathrm{SpO}_{2} 92 \%$. NIV was disconnected only during feeding. Weight reduction also being a potential therapy to improve patients' long-term medical condition, injection liraglutide $3 \mathrm{mg}$ subcutaneous once daily with a plan to escalate dose from $0.6 \mathrm{mg}$ to $3 \mathrm{mg}$ each week from day 2 was considered.

The patient was monitored closely with hourly recording of all vitals; $\mathrm{ABG}$ was repeated at $2 \mathrm{~h}, 4 \mathrm{~h}$, and every $6 \mathrm{~h}$ [Table 2]. After $70 \mathrm{~h}$ of continuous NIV, the patient's clinical condition improved significantly, along with a reduction in $\mathrm{PCO}_{2}$ to $42.8 \mathrm{mmHg}$. The reduction in $\mathrm{PCO}_{2}$ over $70 \mathrm{~h}$ of NIV is shown in Figure 2. The post-NIV ABG result at the $6^{\text {th }} \mathrm{h}$ was within normal range. The patient was discharged to the ward on day 8 as shown in Figure 3. 
Alwadai, et al.: Noninvasive ventilation in extreme super super obese

\begin{tabular}{|c|c|c|c|c|c|c|c|c|c|c|c|c|c|c|c|}
\hline \multirow[t]{2}{*}{ Parameter } & \multirow{2}{*}{$\begin{array}{c}\text { Before } \\
\text { NIV }\end{array}$} & \multicolumn{14}{|c|}{ NIV-70 h } \\
\hline & & At $2^{\text {nd }}$ & At $4^{\text {th }}$ & At $10^{\text {th }}$ & At $16^{\text {th }}$ & At $22^{\text {th }}$ & At $28^{\text {nd }}$ & At $34^{\text {th }}$ & At $40^{\text {th }}$ & At $46^{\text {th }}$ & At $52^{\text {nd }}$ & At $58^{\text {th }}$ & At $64^{\text {th }}$ & At $70^{\text {th }}$ & $\begin{array}{c}\text { At } 6^{\text {th }} \\
\text { post-NIV }\end{array}$ \\
\hline HR & 120 & 125 & 126 & 120 & 110 & 108 & 106 & 105 & 100 & 98 & 98 & 96 & 95 & 93 & 92 \\
\hline BP & $150 / 90$ & $155 / 99$ & $150 / 90$ & $148 / 92$ & $145 / 90$ & $145 / 90$ & $143 / 88$ & $145 / 88$ & $145 / 85$ & $140 / 80$ & $140 / 80$ & $138 / 80$ & $135 / 77$ & $135 / 75$ & $137 / 75$ \\
\hline RR & 40 & 35 & 32 & 30 & 27 & 27 & 25 & 25 & 23 & 25 & 23 & 24 & 22 & 22 & 22 \\
\hline $\begin{array}{l}\text { ABG } \\
\text { (samples) }\end{array}$ & ABG (1) & $\begin{array}{c}A B G \\
(2)\end{array}$ & $\begin{array}{c}A B G \\
(3)\end{array}$ & $\begin{array}{c}A B G \\
(4)\end{array}$ & $\begin{array}{c}A B G \\
(5)\end{array}$ & $\begin{array}{c}A B G \\
(6)\end{array}$ & $\begin{array}{l}\text { ABG } \\
(7)\end{array}$ & $\begin{array}{c}\text { VBG } \\
(8)\end{array}$ & $\begin{array}{l}\text { VBG } \\
(9)\end{array}$ & $\begin{array}{l}\text { VBG } \\
(10)\end{array}$ & $\begin{array}{l}\text { VBG } \\
(11)\end{array}$ & $\begin{array}{l}\text { VBG } \\
(12)\end{array}$ & $\begin{array}{l}\text { VBG } \\
(13)\end{array}$ & $\begin{array}{l}A B G \\
(14)\end{array}$ & VBG (15) \\
\hline $\mathrm{pH}$ & 7.15 & 7.12 & 7.17 & 7.17 & 7.26 & 7.31 & 7.43 & 7.40 & 7.44 & 7.44 & 7.38 & 7.38 & 7.40 & 7.44 & 7.44 \\
\hline $\mathrm{pCO}_{2}$ & 113 & 136 & 121 & 102 & 89.5 & 84.6 & 67.6 & 61.6 & 57.0 & 51.9 & 55.7 & 53.6 & 49.1 & 42.8 & 48.1 \\
\hline $\mathrm{pO}_{2}$ & 65 & 77.3 & 73.8 & 70.2 & 68.8 & 54.0 & 68.0 & 40.2 & 50.2 & 42.4 & 57.1 & 41.6 & 54.4 & 87.9 & 58.2 \\
\hline $\mathrm{HCO}_{3}$ & 27.6 & 29.6 & 31.4 & 27.3 & 32.1 & 35.1 & 40.6 & 34.2 & 35.9 & 28.9 & 29.5 & 28.5 & 28.5 & 28.5 & 31.4 \\
\hline $\mathrm{SPo}_{2}$ & 86.5 & 91 & 91.3 & 91 & 92.4 & 86.4 & 95.4 & 75.3 & 84.9 & 75.3 & 88.8 & 74.9 & 86.2 & 95.6 & 89 \\
\hline
\end{tabular}

NIV: Noninvasive ventilation, ABG: Arterial blood gas, VBG: Venous blood gas, HR: Heart rate, BP: Blood pressure, RR: Respiratory rate

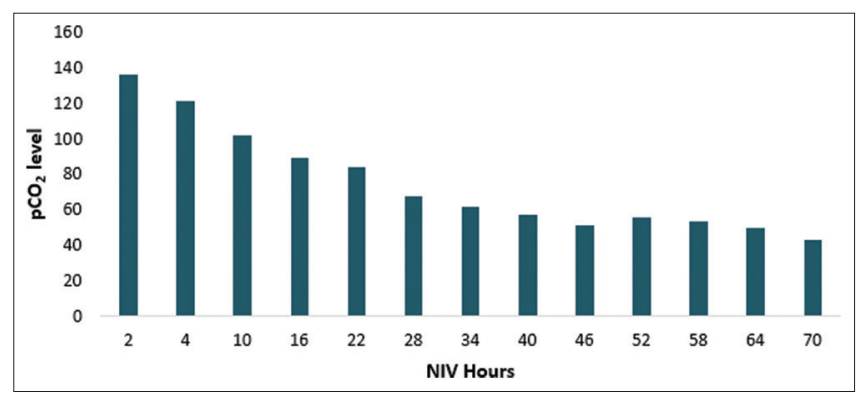

Figure 2: Differential effect of $\mathrm{PCO}_{2}$ reductions over noninvasive ventilation hours

\section{Discussion}

In addition to conventional treatment, NIV was the dominant part of the successful management of this patient. Some obese patients with respiratory etiology are misdiagnosed with chronic obstructive pulmonary disease (COPD) and asthma ${ }^{[5]}$ Similarly, this patient was initially diagnosed and treated as exacerbation of COPD although the clinical diagnosis supported OHS. Physicians should be more cautious about the diagnosis of OHS in this background. In comparison with OSA or eucapneic obese patients, the central fat distribution is found to be higher in OHS, and their respiratory muscles are primarily affected by hypoventilation, larger neck circumference, and high waist: hip ratios. ${ }^{[8]}$ Notably, in this case, the higher central fat distribution reduced the respiratory muscle efficiency, resulting in more significant reduction in lung volume and increased WOB. These features worsened in lying and supine positions due to the cephalic displacement of the diaphragm. Hence, high Fowler's position was adopted for $70 \mathrm{~h}$ of NIV (Bi-level ST). $\mathrm{PCO}_{2}$ reduction was significant as shown in similar studies demonstrating consistent improvement in awake blood gases and daytime sleepiness with NIV as compared to continuous positive airway pressure (CPAP). ${ }^{[8,9]}$ This patient required higher positive end-expiratory pressure of $10 \mathrm{cmH}_{2} \mathrm{O}$ and a higher IPAP of $22 \mathrm{cmH}_{2} \mathrm{O}$ for longer duration before reduction of $\mathrm{PCO}_{2}$ to below $50 \mathrm{mmHg}$ could be achieved. Many comprehensive studies conclude the same

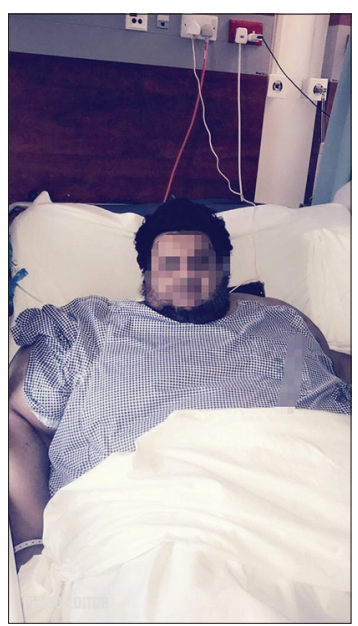

Figure 3: Body mass index $>92 \mathrm{~kg} / \mathrm{m}^{2}$ and excess fat distribution in the region of thorax and neck

result that the NIV is beneficial; it can prevent intubation and associated complications in selected patients. NIV not only enhanced the pulmonary gas exchange but also reduced a load on inspiratory muscles and improved the respiratory mechanics of our patient. In the long term, weight reduction is helpful. ${ }^{[10,11]}$

\section{Conclusion}

The NIV was beneficial in this extreme super-super obese patient with BMI $>92 \mathrm{~kg} / \mathrm{m}^{2}$ with OHA who presented with Type II respiratory failure. NIV prevented intubation and mechanical ventilation complications. Physicians should be aware that each obese patient may not be a candidate for NIV. Awake hypercapnia and hypoxia may persist despite the effective use of NIV. A randomized controlled trial on the use of NIV is recommended in this group of patients.

\section{Declaration of patient consent}

The authors certify that they have obtained all appropriate patient consent forms. In the form the patient has given his consent for his images and other clinical information to be 
reported in the journal. The patient understands that his names and initials will not be published and due efforts will be made to conceal his identity, but anonymity cannot be guaranteed.

\section{Acknowledgment}

The authors would like to thank Dr. Mohammed for his support.

\section{Financial support and sponsorship}

Nil.

\section{Conflicts of interest}

There are no conflicts of interest.

\section{RefERENCES}

1. World Health Organization. Diabetes Country Profiles. World Health Organization; 2016. Available from: http://www.who.int/diabetes/ country-profiles/sau_en.pdf. [Last accesssed on 2019 Sep 26].

2. Obesity Medicine Association; 2019. Available from: https://www. obesitymedicine.org. [Last accesssed on 2019 Sep 26].

3. Global Health Advisory. GHO Data; 2019. Available from: http://who. int/bmi/index. [Last accesssed on 2019 Sep 26].

4. Duran PA, Aragon FJ, Menendez CL, Quintero RM, Pardo LC, Sanchez PC, et al. Bariatric surgery: The radiologist on the hunt for leaks. Eur Soc Radiol ECR2013/C-0198. doi: 10.1594/ecr2013/C-0198.

5. Masa JF, Pépin JL, Borel JC, Mokhlesi B, Murphy PB, Sánchez-Quiroga MÁ, et al. Obesity hypoventilation syndrome. Eur Respir Rev 2019;28. pii: 180097.

6. Alqarni SS. A review of the prevalence of obesity in Saudi Arabia. J Obes Eat Disord 2016;2:2.

7. Al-Nuaim AR, al-Rubeaan K, al-Mazrou Y, al-Attas O, al-Daghari N, Khoja T, et al. High prevalence of overweight and obesity in Saudi Arabia. Int J Obes Relat Metab Disord 1996;20:547-52.

8. Lemyze $M$, Taufour $P$, Duhamel A, Temime J, Nigeon O, Vangrunderbeeck N, et al. Determinants of noninvasive ventilation success or failure in morbidly obese patients in acute respiratory failure. PLoS One 2014;9:e97563.

9. Piper AJ, Grunstein RR. Obesity hypoventilation syndrome: Mechanisms and management. Am J Respir Crit Care Med 2011;183:292-8.

10. Benditt JO. Novel uses of noninvasive ventilation. Respir Care 2009;54:212-9.

11. Chanda A, Kwon JS, Wolff AJ, Manthous CA. Positive pressure for obesity hypoventilation syndrome. Pulm Med 2012;2012:568690. 